\title{
Technical and Economic analysis of a Regulatory Call for PV Plants with Energy Storage in French Islands
}

\author{
A. Chagnard, B. Francois \\ Univ. Lille, Arts et Metiers Paristech, Centrale Lille, HEI, EA 2697 - L2EP, Laboratoire d'Electrotechnique et \\ d'Electronique de Puissance, F-59000 Lille, France \\ alban.chagnard@centrale.ec-lille.fr, bruno.francois@centralelille.fr
}

\begin{abstract}
European incentive policies led to a faster development of renewable energy sources. This energy transition is bringing new challenges, in particular for grid stability. Photovoltaic energy combined with electrical storage system is one of the most promising technology to enable a massive insertion of green energy into the grid. The task of this paper is to study a call for tender launched by the French government in French insular regions, to develop PV plants equipped with electrical storage systems. The technical sizing will be carried on, using the software PVsyst. Then, the energy flows between the PV panels, the battery and the grid will be optimized thanks to an algorithm. The purpose is also to study the benefits and costs of such a system, and so different scenario will be considered, each one leading to a different economic interest. More broadly, this paper considers the role of batteries today, and how it should be rewarded or compensated for service delivery.
\end{abstract}

\section{Key words}

PV energy, storage, regulation, lithium-ion battery; economic indicators, optimization

\section{Introduction}

Renewable energy is taking each year a wider place in the global energy mix. In 2017, $178 \mathrm{GW}$ of renewable energies were installed and is a record-breaking. This huge development is the result of two main factors. First, a global decrease of the costs, making energy sectors like solar or wind power more and more competitive. But, this rise is also due to new political incentives, which encourage renewable energy development through different types of financial help. As solar and wind energy are intermittent sources and not controllable, it is not reasonable to consider a mix of energy of $100 \%$ intermittent renewable energy without a storage system for real time power balancing and energy reserve provision [1, 2]. This paper aims at determining whether an electrical storage system can be profitable today, and under which conditions. This study is driven by considering an existing call for tender, and to do as if a producer wanted to answer to the call for tender, including in his answer an electrical storage system.

\section{The Call for tender by the French regulator}

\section{A. Evolution of feed-in tariffs}

The purchase of renewable energy in France is subsidized by the French government, and supervised by the French regulator: CRE (Commission de Régulation de l'Energie). For solar generation above $100 \mathrm{kWp}$, the capacities are delivered through tenders with a feed-intariff. The electricity, which is produced by the PV plant will be bought by the national company EDF at a fixed price, usually for 20 years. This price is defined in the answer to the call for tender, and enables the CRE to rank the proposals made by private companies, and to choose projects with lower prices. The price is not the unique criterion; environmental criteria are also often included in the selection process.

The European Community advices that renewable energy be also progressively exposed to market competition. To this end, the feed-in tariffs shall progressively be replaced. The tendency is to implement a compensation mechanism in order to allocate a premium tariff to renewable electricity producers on top of the sale price they get on the electricity market, in order to cover the costs of their installations and ensure their profitability. This action should enable a correct payback for PV producers in response to their added environmental value regarding other technologies emitting $\mathrm{CO} 2$.

Anyway, technical problems resulting from massive connexion of PV generators have also to be solved [3]. We can distinguish problems concerning the operation of electrical networks (voltage regulation, peak currents in lines, ...) and problems concerning the balancing between production and consummation. The development of flexibilities as demand management, power control of renewable generators, storage, aims at solving both types of problems.

B. The hybrid storage PV call in French insular regions Grid integration of intermittent renewable energy is particularly critical in islands because of their small power system size and so high sensibility to fast dynamics of power flows [4]. In order to strength both renewable energy and new flexibilities for grid operators, the CRE has published in 2017 [5] a call for tender regarding installations of solar plants of more than 100 
$\mathrm{kWp}$ including a storage system, which is own and managed by the PV producer. The targeted and asked grid flexibility is to deliver electrical energy during demand peak hours for a bonus of $200 € / \mathrm{MWh}$. Hence, the producer has to guarantee during peak hours the delivery of energy of at least equal to $20 \%$ of the rated installed PV power, otherwise penalties will be applied.

With these prescribed technical economic rules, the presented R\&D work consists in sizing an hybrid storage PV installation and to assess the economic value by considering historical input data .

\section{Solar sizing}

\section{A. Presentation of the study case}

The studied plant is located near Saint-André, on the Reunion Island. This region has a strong rate of renewable energy penetration, and a huge solar potential. Since the land surface is limited, the electrical network is less dense than on the European continent, and there is therefore a special need or peak demand shaving and curtailment of intermittent renewable energy production. Storage systems such as batteries can help to balance the supply of electricity3.

For the sake of simplification, the rated power of the plant is defined as $1 \mathrm{MWp}$. For this location, the optimal inclination of solar panels that maximizes the yearly yield is $22^{\circ}$. The azimuth, which corresponds to the orientation of the panels, is optimal for $0^{\circ}$ North, which is common for a South-hemisphere plant [6]. It is then possible to calculate the monthly solar irradiation, which will be used for PV plant sizing. The study assumes that there is no shadow. The irradiation on an optimally inclined plan is $5600 \mathrm{Wh} / \mathrm{m}^{2} /$ day, with a diffusion ratio to global irradiation of 0.39 .

\section{B. Used equipment}

The three main devices of the system are the solar panels, the inverters and the storage system.

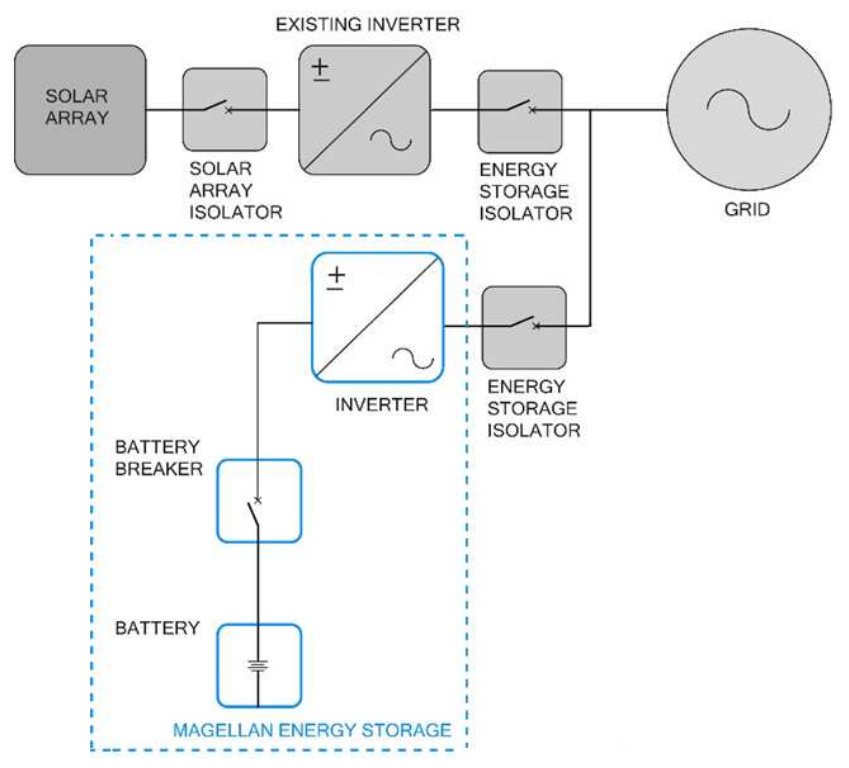

Figure 1. Scheme of the system [7].

Among the different PV technologies, the polycrystalline silicon technology is well adapted to a high rate of sunshine such as the one in the Reunion Island.
Polycrystalline silicon modules CS6K-260P-PG from the company Canadian Solar are considered for the study. This 260W module has entered in the market in 2016, and presents a very good price-quality ratio [8].

Two types of inverter can be used - string inverters or a central inverter. In order to mitigate the risks of a main failure, string inverters will be used. The characteristics of the TRIO 27.6-TL-OUTD inverter from ABB are selected [9] and include two MPPT inputs.

One original goal of this work is to size the storage system in order to maximize the benefits. In a fastchanging market, it is quite difficult to get costs of storage system, like the price of a battery as a function of the energy or the power. Nevertheless, Tesla provides an offer, called Powerpack, for which it is possible to set up the energy and power wanted, and to get the price corresponding to the whole system [10]. For this reason the storage sizing will be done with the Powerpack characteristics and prices.

\section{PVsyst sizing}

The photovoltaic software PVsyst is used in this study to size and simulate the system [11]. After entering the weather data as well as the characteristics of devices, the number of solar panels and string inverters is first computed, making sure that panel voltages and currents are compatible. In order to reach $1 \mathrm{MWp}, 3828$ photovoltaic modules are required. The plant will be composed of 174 strings in parallel, each string including 22 modules in series. 29 inverters are needed for the system, one inverter for 6 strings.

The simulation shows that the annual energy delivered to the grid is $1669 \mathrm{MWh}$, taking into account losses between the irradiate energy and the produced grid electricity. This corresponds to a $19 \%$ load factor.

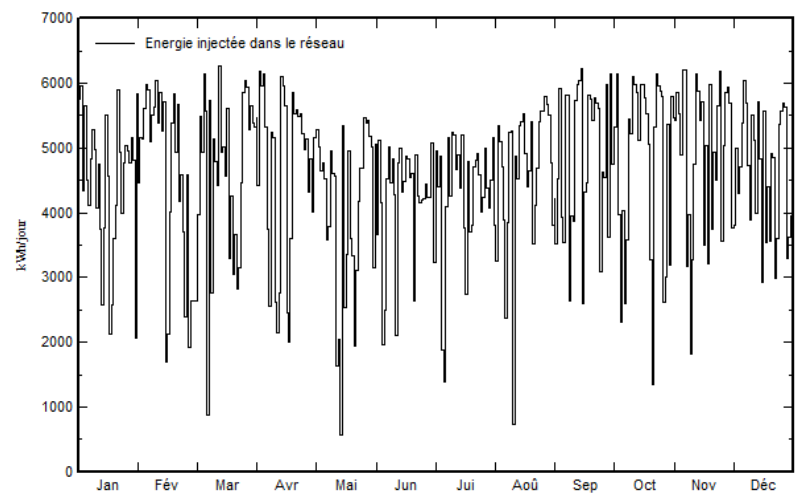

Figure 2. Daily energy delivered to the grid.

\section{Optimization of the energy flows \\ A. Principle}

The objective is to optimize the energy flows between the panels, the battery and the grid in order to maximize the benefits from the sale of electricity [12]. In order to do so, an energy management of the battery is proposed. The flows will be optimized on a daily basis, with a 10 min time step. Production data is imported directly from PVsyst. The call for tender enables to be paid higher during peak hours, which are from $6 \mathrm{pm}$ to $8 \mathrm{pm}$ on the Reunion Island. Thus, the management algorithm will consider a day starting at $8 \mathrm{pm}$ the day ahead and ending 
at $8 \mathrm{pm}$ the D-day. The basic principle is to charge the battery from $8 \mathrm{pm}$ the day before to $6 \mathrm{pm}$, and then to discharge it in peak hours.

\section{B. Constraints and hypothesis}

Several constraints and hypothesis should be highlighted. The optimization assumes that the future is certain, which means that the day ahead forecasts are accurate [13]. The call for tender requires at any time not to deliver to the grid a power above $70 \%$ of installed peak power. As said before, the energy between $6 \mathrm{pm}$ and $8 \mathrm{pm}$ will be paid with a bonus of $200 € / \mathrm{MWh}$. The study first assumes a storage power of $0.7 \mathrm{MW}$ and a storage energy of 1.4 MWh. It will be demonstrated later on that this choice is the most accurate one.

The feed-in-tariff is to be defined by the company willing to answer to the call for tender. This price should not be too low in order to ensure a positive benefit, and not too high in order to win the call for tender. An analysis of the previous calls for tender was carried on, and a price of $130 € / \mathrm{MWh}$ is considered to be a good compromise. This price will be used for the study.

\section{Buying electricity from the grid}

Before starting the optimization process, one question has to be asked: should the purchase of energy from the grid be allowes and be part of the optimization strategy ? In other words, is it possible to load the battery from the grid (and not from the PV production) ? The call for tender authorizes a maximum power of $50 \mathrm{~kW}$ to be taken from the grid. In order to minimize the costs, the study focuses on a subscription to a $36 \mathrm{~kW}$ power (limit of the universal tariff in the Reunion). The purchase price for this subscription is around $142 € / \mathrm{MWh}$ in peak hours, $116 € / \mathrm{MWh}$ in off-peak hours. The annual subscription costs $690 €$. Compared to the feed-in-tariff of $130 € / \mathrm{MWh}$, only the purchase of electricity in off-peak hours, which is from 9:45 pm to 5:45 am, is profitable. Assuming that the system takes energy from the grid from 8 hours at a power of $36 \mathrm{~kW}$, the annual benefit would then be $830 €$. Comparing to the total expected benefit of the plant (which will be calculated after), this benefit is negligible, and the optimization will eventually not include the purchase of electricity on the grid.

\section{Optimization strategy}

The idea is to optimize the flow for one day, in a first loop that will optimize all the days of the years, in a second loop that will optimize each year during 20 years, taking into account the yield degradation. The implementation of this optimization strategy is described thereinafter.

From $8 \mathrm{pm}$ the day before to $6 \mathrm{pm}$, the energy produced by the solar panels is injected in the grid, respecting the following actions.

When the PV power is above $70 \%$ of the installed peak power, the remaining energy is stored.

If at $6 \mathrm{pm}$ the battery is not full with the first action, the energy produced at step 5:50 pm is stocked, then the one at $5: 40 \mathrm{pm}, 5: 30 \mathrm{pm}$, and so on until the battery is able to deliver an energy at a power of $70 \%$ of installed peak power from 6:00 $\mathrm{pm}$ to 8:00 $\mathrm{pm}$.
From 6:00 pm to $8: 00 \mathrm{pm}$, the battery delivers its energy so that the total power of the panels and the battery does not exceed $70 \%$ of installed peak power.

For each day of the year, it is possible to verify that:

- All the energy coming from a PV power above $70 \%$ of the installed peak power is stored.

- The sum of PV power and storage power is never greater than $70 \%$ of the installed peak power.

- The delivered power during peak hours is always greater than $20 \%$ of installed peak power (minimum reached: $25.3 \%$ of installed peak power).

\section{E. Results}

The developped code enables to see the different energy flows between PV modules, the storage system and the grid, as well as the state of charge of the battery.

For the optimization on one day, a typical graph of results is presented thereinafter.

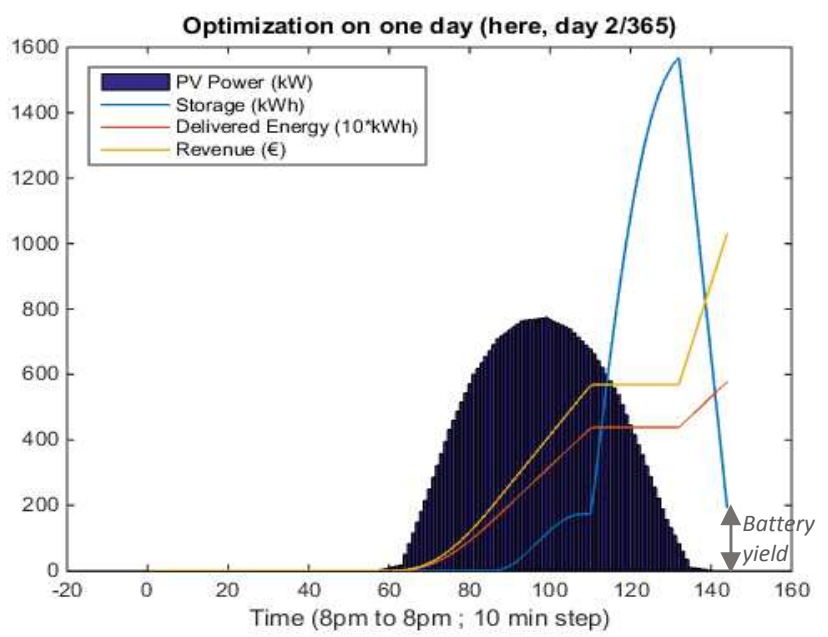

Figure 3. Example of results for one day

For the optimization on one year, a typical graph of results is presented thereinafter.

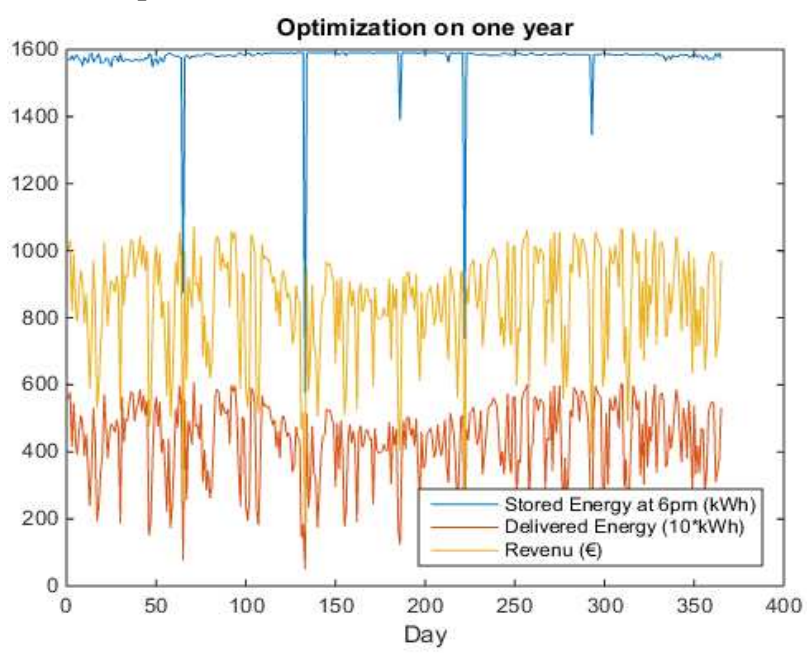

Figure 4. Example of results for one year

The previous results were obtained for a $0.7 \mathrm{MW}$ storage power of and a 1.4 MWh storage energy (losses deduced). In the algorithm, it is possible to change these values in order to see the impact of the storage sizing on the overall performance of the system. An optimization algorithm could be implemented in order to maximize the benefits by changing both power and energy value of the 
storage. Nevertheless, it is possible to establish that only three scenarios are likely to be optimal.

\section{Storage sizing}

Taking into account the constraints from the call for tender, which energy management strategy for the storage could be implemented?

The first scenario to study is a PV plant without storage. As the cost of storage is still rather expensive, it is not certain that the use og a storage system will be profitable, even with a $200 € / \mathrm{MWh}$ bonus during the two peak hours. At least, it is necessary to compare this scenario to the scenarios with storage.

One of the advantage of a storage system is to be able to store the energy produced when the PV power is above $70 \%$ of the installed peak power. Otherwise, because of the constraint coming from the call for tender, this energy would be lost.

A second strategy is therefore to size the battery so that a majority of this energy is stored. The optimal sizing is obtained for a $50 \mathrm{~kW}$ battery power and a $100 \mathrm{kWh}$ battery energy. With this sizing, it is nonetheless not possible to benefit from the tariff bonus, because the producer cannot guarantee the delivering of energy with at least $20 \%$ of installed peak power during peak hours.

The third sizing strategy is to size the storage system in order to deliver $70 \%$ of installed peak power during peak hours, and therefore to take the maximum advantage of the tariff bonus. Since the PV production from $6 \mathrm{pm}$ to $8 \mathrm{pm}$ is very weak, the sizing for this strategy is a $0.7 \mathrm{MW}$ battery power and a 1.4 MWh battery energy.

There is no other viable sizing strategy for two reasons. Only the range $6 \mathrm{pm}-8 \mathrm{pm}$ benefits from a tariff bonus, so there is no point in oversizing the storage system compared to the third scenario. If the price of storage is considered as a linear function of the power or the energy - and this assumptions can reasonably be made - either the tariff bonus is profitable and the third scenario is optimal, or the tariff bonus is not profitable and the first or second scenario is optimal. An in-between strategy is therefore to exclude.

\section{Technical-economic analysis}

\section{A. Investment and costs}

For each strategy, an economic analysis was done, based on the technical results given by the algorithm. A list of financial assumptions first had to be made. The discounting rate is taken as $1.5 \%$, as recommended by the OECD (Organisation for Economic Co-operation and Development). The plant is sized for 20 years, and the replacement of devices should appear in the financial statement. For inverters and batteries, the renewing time is 10 years, which is a rather pessimistic assumption. As the prices of inverter and battery on the market will go down with the years, the study considers that in 10 years there will be a decrease of $34 \%$ of the price of battery [14], and $30 \%$ of the price of inverter [15]. The CAPEX and OPEX can then be calculated for each scenario. Thereinafter is an example of the financial table for the third scenario, which includes investment and costs.

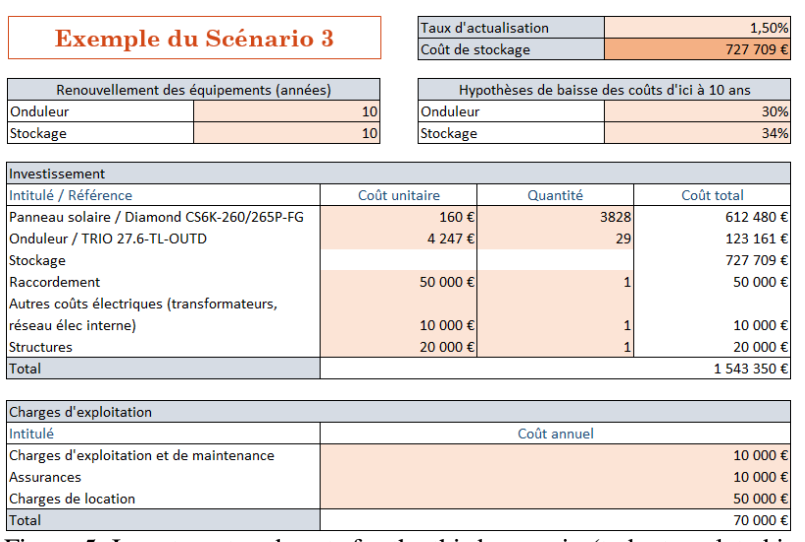

Figure 5. Investment and costs for the third scenario (to be translated in english)

\section{B. Results}

Using the code as well as the financial table, it is possible to get the power and economic results for each scenario (figure 6).
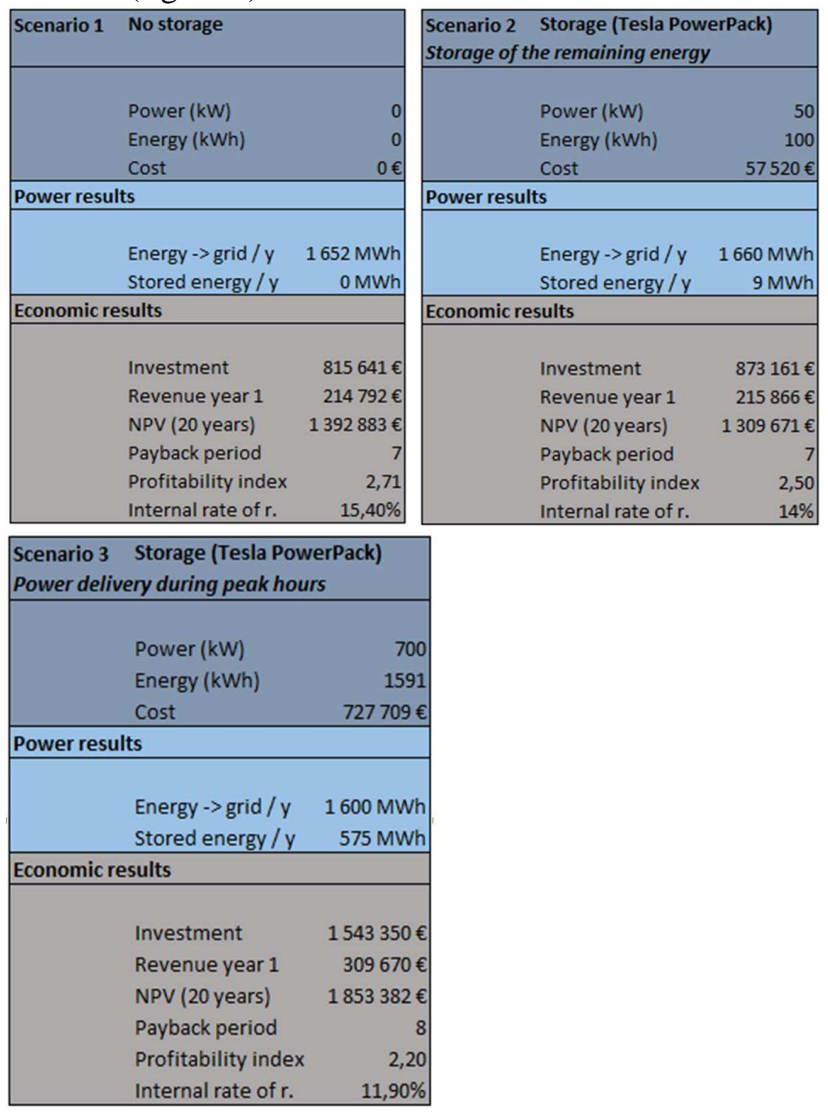

Figure 6. Results from each scenario

On these results (figure 6), it is first possible to see the difference of battery investment, none for Scenario 1 and max for Scenario 3.

Two important power results are the energy delivered to the grid, as well as the stored energy.

The economic analysis can be made by using several indicators, this is why the Net Present Value (NPV), Discounted Payback Period (DPP), Profitability Index (PI) and Internal Rate of Return (IRR) are calculated.

It can be noticed that the energy delivered to the grid is less important for the Scenario 3, which is the result of the battery losses. The lost energy in Scenario 1, which corresponds to the energy for a power above $70 \%$ of the nominal power of the plant, represents only $1 \%$ of the 
total energy. $55 \%$ of this energy is stored and delivered in Scenario 2.

It appears that the Scenario 2 is clearly less interesting than the two others. Between the Scenario 1 and 3 (without and with storage), all the economic indicators do not give the same result.

\section{Choice of scenario}

Both Scenario 1 and 3 appears as good choices, and it is not obvious to choose between the two. The major difference is the amount of investment. The investment for Scenario 3 is almost the double of Scenario 1 because of the storage system. As a result, the Scenario 1 has a better DPP, PI and IRR. Nevertheless, the NPV of Scenario 3 is greater than the NPV of Scenario 1.

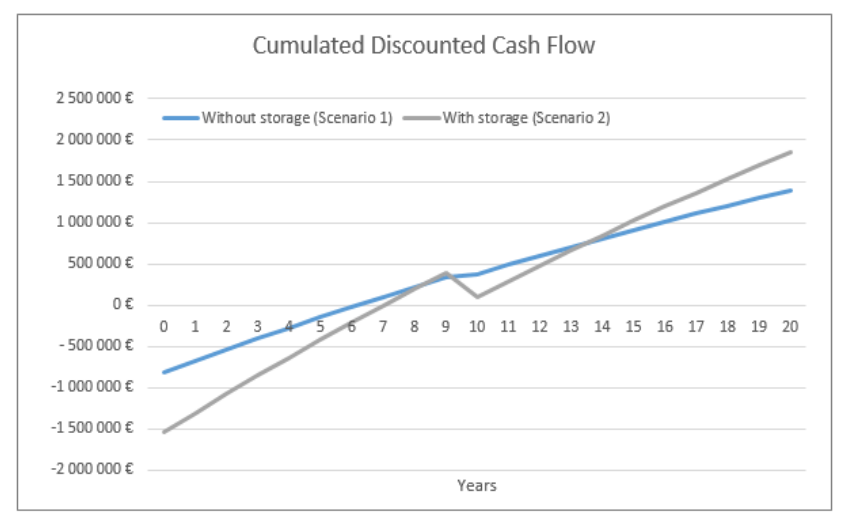

Figure 6. NPV of Scenario 1 and 3

It could be tempting to choose Scenario 1, because the money earned per euro invested is greater, and the payback period is lower. However, except under capital rationing, the NPV indicator should be preferred, because it is the only indicator that reflects the net increase in the firm's wealth. In other words, at the end of the 20 years Scenario 3 will earn more money than Scenario 1 . As a result, the storage system is profitable and should be implemented on this solar plant.

\section{Conclusion}

The call for tender in French insular regions is an interesting case, because it enables producers to think about including a storage system within the solar plant. Thanks to a technical and economic study, it was demonstrated that a storage system is profitable on the Reunion Island. However, it should not be forgotten that so far the only reason that makes the storage system profitable is the very rewarding tariff bonus of 200€/MWh during peak hours. It is possible to show that the limit of profitability of the storage system is obtained for a tariff bonus of $149 € / \mathrm{MWh}$ for this plant under the assumptions used (equality of NPV of Scenario 1 and 3). This shows that battery costs are today still too high, but they are expected to sharply decrease in the coming years. Today for a producer using a storage system, it is necessary to be paid not only for the energy delivered but also for the service provided to the power system, such as peak shaving.

Self-consumption policies and regulations are the core for the future devlopement of local energy communities. Anyway electrical network constraints remain to be checked [16]. Satisfying these constraints is not trivial in this context and opens great interesting future research trends [17].

\section{References}

[1] B. Robyns, B. Francois, G. Delille, C. Saudemont, "Energy Storage in Electric Power Grids“, Wiley, 2015, ISBN : 978-184821-611-2

[2] G. Delille, B. Francois, G. Malarange, J.L. Fraisse, Energy storage systems in distribution grids: New assets to upgrade distribution network abilities, CIRED 2009, 8-11 June, 2009, Prague

[3] B. Robyns, A. Davigny, B. Francois, A. Henneton, J. Sprooten, “ Electricity Production from Renewables Energies“, Wiley, 2012, ISBN 978-1-84821-390-6

[4] H. Bevrani, B. Francois, T. Ise, "Microgrid Dynamics and Control“", Wiley, 2017, ISBN: 978-1-119-26367-8

[5] CRE, website of CRE, call for tender available on: http://www.cre.fr/documents/appels-d-offres/appel-d-offresportant-sur-la-realisation-et-1-exploitation-d-installations-deproduction-d-electricite-a-partir-de-techniques-de-conversion-durayonnement-solaire-d-une-puissance-superieure-a-100-kwc-etsituees-dans-les-zones-non-intercon2

[6] European Commission, PV Potential Estimation Utility, http://re.jrc.ec.europa.eu/pvgis/apps4/pvest.php?lang=en\&map=af rica\#

[7] Solar choice, homepage, https://www.solarchoice.net.au/

[8] Canadian Solar, Data sheet, http://www.canadiansolar.com/downloads/datasheets/na/Canadian _Solar-Datasheet-CS6KPFG_Diamond-v5.3_na.pdf

[9] ABB, Data sheet of string inverters, https://library.e.abb.com/public/6ae11b86a2044360c1257da10034 a0ef/TRIO-27.6-JP BCD.00578 EN Rev\%20B.pdf

[10] Tesla, Powerpack, https://www.tesla.com/fr_FR/powerpack

[11] PVsyst, PVsyst homepage, http://www.pvsyst.com

[12] D. Lu, T. Zhou, H. Fakham, B. Francois, Design of a power management system for an active PV station including various storage technologies, EPE/PEMC: 13th International Power Electronics and Motion Control Conference, Poznan, Poland, 1 - 3 September 2008

[13] X. Yan, D. Abbes, B. Francois, Solar radiation forecasting using artificial neural network for local power reserve, International Conference on Electrical Sciences and Technologies in Maghreb (CISTEM), 2014

[14] Automobile propre, battery cost, http://www.automobilepropre.com/breves/prix-batteries-li-ion-baisser-35-pourcent-2025tesla-favori/

[15] PV magazine USA, inverter cost, https://pv-magazine-usa.com/2016/12/08/global-invertershipments-to-contract-5-in-2017-before-steady-recovery-saysgtm-research/

[16] M.T. Do, B. Francois, "Probabilistic approach to evaluate the cost and constraints of the renewable production curtailment in MV network", IFAC 2017 World Congress, 2017, July 9-14, Toulouse, France

[17] V. Pailloux, B. Francois, Mitigation analysis of MV distribution network constraints thanks to a self-consumption policy for photovoltaic distributed unit, IEEE PES Powertech 2019, 23 -27 June, Milano, Italy 